UDC 533.9.004.14; 621.039.6

\author{
${ }^{1 *}$ Zhukeshov A.M., ${ }^{1}$ Ibraev B.M., ${ }^{2}$ Giniyatova Sh.G., \\ ${ }^{3}$ Useinov B.M., ${ }^{4}$ Nikulin V.Ya., ${ }^{1}$ Gabdullina A.T., ${ }^{1}$ Amrenova A.U. \\ ${ }^{1}$ IETP, al-Farabi Kazakh National University, Almaty, Kazakhstan \\ ${ }^{2}$ Faculty of Physics and Technology, L.N.Gumilyov Eurasian National University, Astana, Kazakhstan \\ ${ }^{3}$ North Kazakhstan State University named M. Kozybaev, Petropavlovsk, Kazakhstan \\ ${ }^{4}$ Lebedev Physics Institute, Moscow, Russia \\ "e-mail: zhukeshov@physics.kz
}

\title{
Parameters calculation and design of vacuum camera for «Plasma focus» facility
}

\begin{abstract}
Abstrac: Evaluation of discharge current magnitude and circuit discharge dynamics was performed on the basis of electrodynamic model for designed «Plasma focus» facility. This work investigates dependence of plasma focus current, plasma conductivity and electrons temperature on electrical engineering parameters of reactor (voltage, capacity and size of electrode system). Using obtained data, calculation of electrode system geometry was carried out. Vacuum camera for experimental research is descripted. Vacuum system of the pilot reactor uses fore vacuum unit and sensor system based on thermocouple and magnetic discharge manometers by Agilent technology. Promising ways to study the plasma focus were showed to solve applied physical problems.
\end{abstract}

Key words: plasma, vacuum camera, plasma focus, electrodynamic, electrode.

\section{Introduction}

So far, attempts of scientists to solve the problem of thermonuclear fusion are generally related to magnetic systems. Tokamaks (ITER project), laser inertial fusion, traps, etc. are exploered for this purpose. All those methods are being developed for tens of years, thousands of scientific papers were published, but no acting reactor is constructed yet.

First of all, it is caused by serious technical difficulties, but there are also fundamental reasons.

One of them is inability to take into consideration coordinated of all individual plasma particles [1] even at low concentration of particle in. In such situation alternative approach to solve this problem is study plasma self-organization taking into account collective. Matters of plasma selforganization in various plasma facilities are just beginning to be examined. For the first time, stratatype structuring of plasma was observed during Zpinch experiments [2]. Structuring in plasma accelerators was also detected $[3,4]$.

In high-temperature dense plasma, selforganized structures shapes as filaments, alternating bands and other organized objects [5]. Obviously, presence of such objects indicates fundamental structuring property of dense hot plasma. In that case, they will play a decisive role in the work of fusion facilities.

Another approach for fusion facilities design is the method based on generation of plasma in apparatuses of plasma-focus type. On the basis of dynamic structures research in various plasma focus facilities, the authors of the project study the matter of design for new-type reactors based on focusing of plasma beams in small area with high density. The idea is that since the system is centrally symmetric this allow to compress plasma to the high dense due to contribution of strong magnetic field of parallel discharge currents and its geometry. For this purpose, shapes of both cathode and anode should be chosen in the way which provides plasma focus in localized area above anode. Magnetic fields focus plasma filaments into bunch which diameter has the size of several millimeters. When the bunch becomes dense enough, the temperature is the order of 100 million degrees that is sufficient for beginning of fusion. Formed in the focus area, the plasma bunch is self-organized structure and conditions of its formation should be thoroughly examined. 


\section{Experimental device and measured methods}

Pilot fusion reactor «Plasma focus», developed by us, includes plasma focus chamber, capacitive energy storage, high-voltage discharger and current supplies. As capacitive energy storage, we use capacitor bank of 24 capacitors IK-50 with voltage of $30 \mathrm{kV}$ and total capacity of $72 m k \mathrm{~F}$ as well as capacitor bank of 4 capacitors IK-50 with voltage of $5 \mathrm{kV}$ and total capacity of $600 \mathrm{mkF}$.

We use two types of central electrode-cathode for plasma focus - in the first case, cylinder with diameter of $3 \mathrm{~cm}$, wall thickness of $3 \mathrm{~mm}$ and length of $10 \mathrm{~cm}$; in the second case, it presents solid round of the same sizes. External electrode -6 cylinders circularly at distance of $2-3 \mathrm{~cm}$ from the center.

Let's briefly consider the theory of the process. During discharge of capacitor bank, current flows through the gas wherein current's plasma sheath is produced passing through the gas toward internal electrode (cathode). Current flows create strong magnetic field. The magnetic field pushes current's plasma sheath along chamber electrodes and presses the current sheath toward the system axis until plasma focus is produced. All stages and parameters of the process (formation of current sheath and magnetic field, processes of current sheath compression, formation of shock wave and plasma focus) depend on electrical engineering parameters [5].

This work investigates dependence of plasma focus current, plasma conductivity and electrons temperature on electrical engineering parameters of reactor (voltage, capacity and size of electrode system). From experimental data analysis, it is found that at given voltage, maximum value of plasma focus current depends on plasma pressure. In the beginning, with pressure increasing (3-6) torr, the current increases almost linearly, reaches its maximum value at the pressure of 6 torr. and then drops down. Increase of current with respect to pressure is caused by the fact that the time of plasma sheath motion is less than quarter period of capacitor bank discharge. Asymmetric breakdown leads to pressure increase. As a result plasma sheath compresses into cord with large inductance, and value of current decreases. From literature data analysis it could be concluded that plasma focus current depends on capacitor bank voltage. Besides, with voltage increasing, the current increases almost linearly that allows us to introduce the value $Y=\frac{d L}{d t}$ as a proportionality factor.

Thus, from the expression $I=\frac{1}{Y} U$, one can conclude that maximal current is determined by capacitor bank voltage and magnitude of circuit inductance change per time. The magnitude is determined by size of electrodes: anode and cathode, along with longitudinal velocity $\frac{d z}{d t}$ of current's sheath. To obtain the highest values for plasma focus current, we need optimum correlation between sizes of anode and cathode and magnitude of longitudinal velocity. With increase of longitudinal velocity of current's plasma sheath, the magnitude of $\frac{d L}{d t}$ initially increases almost linearly, then hits zero value and grows further. Optimum range for velocity values at our facility is velocity value of current's sheath $(4-5) \cdot 10^{3} \mathrm{~m} / \mathrm{s}$ (more precise data will be obtained by probes). Maximal calculated value of plasma focus current is 3.03 MA at capacitor bank voltage of $30 \mathrm{kV}$, pressure $p=(4-6)$ torr and current's plasma sheath velocity $\frac{d z}{d t}=0.417 \cdot 10^{4} \mathrm{~m} / \mathrm{s}$; and the minimal one is 2.53 MA at voltage of $25 \mathrm{kV}$.

Conductivity calculation. Conductivity of plasma depends on electrical engineering parameters: capacitor bank voltage, current, sizes of anode and cathode and discharge time of capacitor bank. If magnitude of inductance change $\frac{d L}{d t}$ is considered constant during discharge $(5 \mathrm{mks})$, conductivity of plasma can be considered constant. The conductivity was calculated using well-known formula where plasma pulse time only changes at specified values of voltage. Calculation showed $9.2 \cdot 10^{3} \mathrm{Om}^{-1} \mathrm{~m}^{-1}$ for conductivity value.

Temperature calculation. The temperature was calculated under two conditions: in the first case, the temperature was calculated under condition that ionization degree is approximately equals $50 \%$ corresponding to current's plasma sheath_formation time. Herewith, electrical conductivity of plasma is only determined by temperature of electrons. Temperature of electrons was determined using Spitzer formula. Calculation showed that order of 
magnitude of plasma temperature is $10 \mathrm{eV}$. In the second case, the temperature was evaluated under condition of constant velocity of radial compression during formation of plasma focus from equality of gas-kinetic and magnetic pressure. Temperature calculation showed $63.7 \mathrm{eV}$ for its maximum value at current of 3.03 MA. The minimum value is 45.2 $\mathrm{eV}$ at current of $2.53 \mathrm{MA}$, wherein concentration of electrons is $n_{e}=10^{13} \mathrm{~m}^{-3}$.

Thus, temperature of plasma will increase by about 6 times in the period from formation of current's plasma sheath till creation of plasma focus.

Calculation for magnetic field intensity. Value of magnetic field intensity that appears during formation of CPS can be evaluated from equality of gas-kinetic and magnetic pressure. Calculations show $H=1.6 \cdot 10^{2} \mathrm{~A} / \mathrm{m}$. As plasma sheath moves, its radius reduces to cord size resulting the sharp increase of magnetic field intensity. For precise calculation of magnetic field intensity, we should measure the magnitude of current's plasma sheath radial compression. Thickness of skin layer makes $1.2 \mathrm{~cm}$.

Energy calculation. Energy saved in capacitor bank provides ohmic heating, magnetic energy, work of ponderomotive forces and motion kinetic energy of particles. Energy of $2 \cdot 10^{3} \mathrm{~J}$ providing heating of plasma is determined by ohmic losses and it is insignificant. Magnetic energy value is about

$80 \mathrm{~kJ}$.

Calculations for the facility using capacitor bank IM-150 with maximum voltage of $5 \mathrm{kV}$ and capacity of $150 \mathrm{mkF}$ per battery showed $300 \mathrm{kA}$ for maximum current and order of $1 \mathrm{eV}$ for plasma focus temperature.

Dependence of discharge current on battery capacity when using capacitors IK-50 is shown in Figure 1.

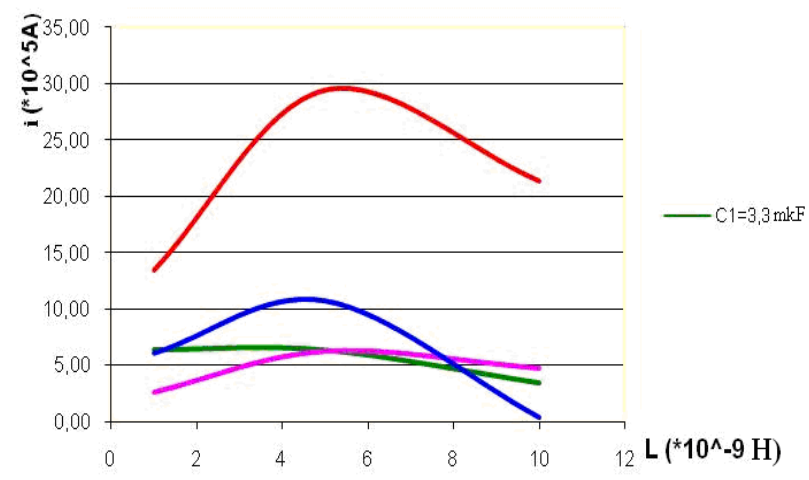

Figure 1 - Discharge curves of current for IK-type capacitors
Figure 2 presents similar diagrams for dependence of discharge current on battery capacity when using capacitors IM-150. As it is seen, maximum value of current can be obtained when system inductance is about $6 \mathrm{nH}$ regardless of capacitor type. Wherein, maximum discharge current differs essentially: being 3MA for IK-50 capacitors, it results $300 \mathrm{kA}$ for IM-150 capacitors and actually allmost does not depend on capacity value.

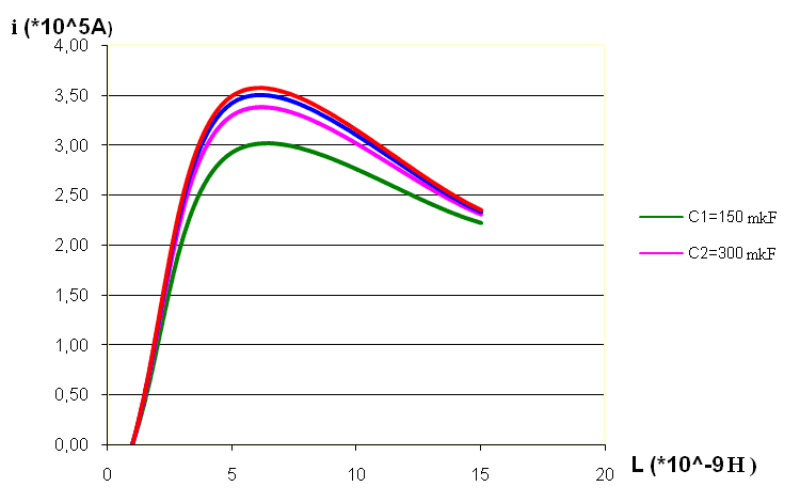

Figure 2 - Discharge curves of current for IM-type capacitors

\section{Conclusions}

«Plasma Focus» facility supposes use of high vacuum and presence of high-vacuum flanges with large diameter. Here, discharge currents can hit hundreds of kiloamperes therefore major requirement is sufficient thickness of chamber walls. Observation glass and diagnostic jacks should be also provided.

The designed facility supposes use of high vacuum and presence of high-vacuum flanges with large diameter. Here, discharge currents can hit hundreds of kiloamperes therefore major requirement is sufficient thickness of chamber walls. Observation glass and diagnostic jacks should be also provided.

Due to complication in design of such chamber in vitro, ready chamber of TMN-500 turbo molecular pump was used. Presence of two flanges by $18 \mathrm{~cm}$ and one flange by $30 \mathrm{~cm}$ in the facility allows total implementation of experiment conditions. The chamber wall thickness makes over $1 \mathrm{~cm}$ and ultimate vacuum is the order of $10^{-9}$ torr

Vacuum system of the pilot reactor uses fore vacuum unit and sensor system based on thermocouple and magnetic discharge manometers by Agilent technology. Vacuum control is managed 
via digital controller 600 of the above trademark. Vacuum improving work and chamber vacuum test are in progress.

\section{Acknowledgment}

This work was supported by the Ministry of Education and Science of KR, grant №3207 GF4.

\section{References}

1. Smirnov V.P. Issledovanija po termojadernomu sintezu // Vestnik RAN. - 1974. - T. 73. S. 6-14.

2. Kvarchava I.F., Kervalidze K.H., Gvaladze Ju.S., Zukakishvili G.G. Prostranstvenno-periodicheskie struktury plazmy, voznikajushhie $\mathrm{v}$ bystryh sil'notochnyh razrjadah // Jadernyj sintez. 1965. - T.5. - № 5. - S.181-191.

3. Francis Y.C., Elkridge R., Smith J., Martin A., Cassibry J., Wu S.T. A Plasma Accelerator Concept for Application to Magnetized Target Fusion // Z-Pinches Conference. - Florence: Alabama university press. - 2006. - P. 456-467.

4. Voronin A.V., Aleksandrov S.E., Ajushin B.B. Snabzhenie toplivom central'noj zony GlobusM s pomoshh'ju plazmennoj pushki // Materialy dokladov 36-oj mezhdunarodnoj konferencii po fizike plazmy i UTS. - Zvenigorod, 2009. - S. 75-78

5. Burcev V.A., Gribkov V.A., Filippova T.I. Vysokotemperaturnye pinchevye obrazovanija. // Itogi nauki i tehniki. Ser. Fizika plazmy. - 1981. T. 2. - S. 226. 